\title{
Klimawandel und Obstanbau
}

\section{W. Dierend}

Online veröffentlicht: 8 August 2009

(C) Springer-Verlag 2009

Der Anbau von Obst erfolgt überwiegend im Freiland und wird daher vom Klima unmittelbar beeinflusst. Das Klima erfährt weltweit Veränderungen. Das Wettergeschehen neigt zunehmend zu großen Gegensätzen. Hitze- und Trockenschäden sind keine Seltenheit mehr. Die Anbaubedingungen für den Obstbau verändern sich. Blüte und Ernte erfolgen früher. Wärmebedürftige Obstarten und -sorten können zunehmend in nördlichen Regionen angebaut werden. Ertragseinbußen durch zu hohe Temperaturen und eine eingeschränkte Wasserversorgung können auftreten. Extreme Wetterereignisse wie z. B. Hagel, Starkniederschläge, Son- nenbrand und Stürme sind die Ursache für weitere direkte Ertragseinbußen. Daneben stehen indirekte Ertragseinbußen durch einen steigenden bzw. sich qualitativ verändernden Befallsdruck durch Schädlinge und Krankheiten.

Das vorliegende Heft widmet sich mit fünf Originalbeiträgen ausschließlich dem Klimawandel und dessen Auswirkungen auf den Obstanbau. Behandelt werden u. a. klimatische Veränderungen der vergangenen Jahrzehnte sowie Auswirkungen auf das Kältebedürfnis, das Auftreten von Fruchtfäuleerregern, die Phänologie und die Blüteninduktion von Obstgehölzen.

W. Dierend (

Fachhochschule Osnabrück, Fakultät Agrarwissenschaften und Landschaftsarchitektur,

Oldenburger Landstr. 24, 49090 Osnabrück, Deutschland

E-Mail: w.dierend@fh-osnabrueck.de

Tel.: +49-541-9695122 